(2) Open Access Full Text Article

\title{
Increased Serum Soluble Interleukin-2 Receptor Associated with Severity of Acute Exacerbation of Chronic Obstructive Pulmonary Disease
}

\section{Yue Zhang (iD) \\ Lianping Ren \\ Jinyuan Sun \\ Fengfeng Han \\ Xuejun Guo}

Department of Respiratory Medicine, Xinhua Hospital Affiliated to Shanghai Jiao Tong University School of Medicine, Shanghai, 200092, People's Republic of China
Correspondence: Xuejun Guo Department of Respiratory Medicine, Xinhua Hospital Affiliated to Shanghai Jiao Tong University School of Medicine, 1665 Kong Jiang Road, Shanghai, 200092,

People's Republic of China

Tel +86-2I-25078999-7373

Email guoxuejun@xinhuamed.com.cn
Background: This study aimed to reveal the correlation between serum soluble interleukin2 receptor (sIL-2R) and prognosis in patients with acute exacerbation of chronic obstructive pulmonary disease (AECOPD).

Methods: A total of 315 patients diagnosed with AECOPD between December 2017 and June 2020 were enrolled. The patients were divided into the good and adverse groups based on the outcomes. An adverse outcome in COPD exacerbation was defined by the presence of at least one of the following: (1) death from a respiratory cause during hospitalisation or within 1 month of follow-up; (2) intensive care unit admission; (3) invasive or non-invasive mechanical ventilation; and (4) COPD-related emergency visit or readmission within 1 month of follow-up. A good outcome was considered as the absence of all the aforementioned issues. The patients underwent lung function (spirometry) assessment, and clinical and inflammatory profiles were collected. Univariate and multivariate analyses were performed to identify the correlation between serum sIL-2R concentration and other variables related to adverse outcomes of AECOPD. The receiver operating characteristic curve was used to show the predictive ability of sIL-2R for adverse outcomes of AECOPD.

Results: We enrolled 315 patients, of whom 161 and 154 had good and adverse outcomes, respectively. We demonstrated that patients with adverse outcomes of AECOPD had a higher concentration of serum sIL-2R than patients with good outcomes $(p<0.001)$. The increased serum sIL-2R was positively associated with mMRC scores $(p<0.001)$, GLOD grades $(p<$ $0.001)$, frequent exacerbation $(p<0.001)$, and smoking $(p<0.001)$ in patients with AECOPD and negatively correlated with pulmonary function $(p<0.001)$. An elevated SIL-2R level was a predictor for the risk of adverse outcomes in AECOPD with a cut-off value of $860 \mathrm{U} / \mathrm{mL}$.

Conclusion: Increased serum sIL-2R concentration correlated with the risk of the adverse outcomes in AECOPD, indicating that it can be a predictive factor contributing to the diagnosis and assessment of adverse outcomes in patients with AECOPD.

Keywords: chronic obstructive pulmonary disease, acute exacerbation, soluble interleukin-2 receptor, predictive factor

\section{Background}

Chronic obstructive pulmonary disease (COPD) is characterised by persistent airflow limitation, which is ranked as a leading cause of death and disability globally. ${ }^{1}$ Acute exacerbation of COPD (AECOPD), punctuating the natural history of COPD, is a major clinical risk factor for increased morbidity and mortality rates in the future. ${ }^{2,3}$ The Global Initiative for Chronic Obstructive Lung Disease (GOLD) has 
stated that the prevention and treatment of exacerbations should be a key goal in COPD management. ${ }^{4}$

Severity, evolutionary process, and results of AECOPD may differ significantly between patients. Several patients have favourable outcomes, in whom the disease can be controlled within a short period, while others may be hospitalised for long periods or may even die. Therefore, the identification of risk factors for unfavourable outcomes could help in distinguishing patients who require more intense management, consequently reducing disability and mortality rates of COPD and improving the patients' quality of life.

Although several clinical factors associated with frequent AECOPD have been identified, ${ }^{5}$ the reasons for adverse outcomes in patients with AECOPD remain unclear. This is because COPD is a complex and heterogeneous disease. In addition to causing local pulmonary inflammation, COPD is a systemic inflammatory disease involving a variety of inflammatory factors. ${ }^{6,7}$ Several studies concerning these inflammatory factors provided various novel ideas regarding the pathogenesis of AECOPD; however, to date, there are no objective biomarkers that can predict the disease activity or adverse outcomes in AECOPD.

Soluble interleukin-2 receptor (sIL-2R) are present at low levels in the sera of healthy individuals, but are further increased in patients with infections, inflammation and autoimmune diseases, so it has been reported and primarily considered as effective markers for measuring disease activity. However, there are few concerns related to the correlation between SIL-2R and COPD exacerbation. This study aimed to determine whether changes in serum sIL$2 \mathrm{R}$ concentrations are related to the severity of disease and may be a predictive factor of disease exacerbations, helping clinicians to distinguish the risk of AECOPD and develop targeted interventions.

\section{Methods}

\section{Ethics Statement}

The study protocol was approved by the Human Research Ethics Committee of the Xinhua Hospital affiliated to Shanghai Jiaotong University Medical College (XHECC-2017-085). Written informed consent was obtained from each participant. This study was conducted in accordance with the Declaration of Helsinki.

\section{Study Subjects}

A total of 315 patients diagnosed with AECOPD between December 2017 and June 2020 from the emergency department or outpatient department of Xinhua Hospital in Shanghai were enrolled, of whom 161 and 154 had good and adverse outcomes, respectively. All the patients enrolled in this study met the diagnostic criteria of the GOLD: ${ }^{4}$ (a) symptoms of cough and dyspnoea; (b) individual susceptibility factors and environmental factors; and (c) forced expiratory volume in the first second/forced vital capacity $\left(\mathrm{FEV}_{1} / \mathrm{FVC}\right)<70 \%$ after inhalation of 400 $\mu \mathrm{g}$ of salbutamol. According to the GOLD document, AECOPD was defined as a recent worsening of respiratory symptoms that required a change in the domiciliary therapy, with the need for hospitalisation based on the severity of COPD exacerbation and presence of indicators.

The exclusion criteria were as follows: documented history of other concomitant chronic respiratory diseases, such as asthma and interstitial lung disease, and pneumonia, tuberculosis, lung cancer, pulmonary embolism, or acute heart failure identified by clinical signs, chest radiograph, or computed tomography at admission.

All patients discharged from our institution following treatment of AECOPD were scheduled for a follow-up visit after 1 month. For reasons concerning the statistical power, we conducted our analysis using data from the first exacerbation in each patient, despite the possibility of more than one admission during the observation period.

An adverse outcome in COPD exacerbation was defined by the presence of at least one of the following: death from a respiratory cause during hospitalisation or within 1 month of follow-up; intensive care unit admission; invasive or non-invasive mechanical ventilation; and COPD-related emergency visit or readmission within 1 month of follow-up. A good outcome was considered as the absence of all the aforementioned issues. The sample number and division are detailed in Figure 1.

\section{Clinical Characterisation}

Demographic and clinical data, including laboratory findings, were collected within $3 \mathrm{~h}$ of admission. The data included the patients' demographic variables, body mass index, smoking habit (former smokers were defined as those who stopped smoking for $\geq 6$ months prior to their participation in this study), and comorbidities (using the Charlson index) ${ }^{8}$ Cigarette smoking history was collected as the smoking index $(\mathrm{SI}=$ pack per day $\times$ smoking years $)$. Furthermore, data on the number of AECOPD in the preceding year was collected. Frequent exacerbation was defined as $\geq 2$ exacerbations per year. Dyspnoea of patients 


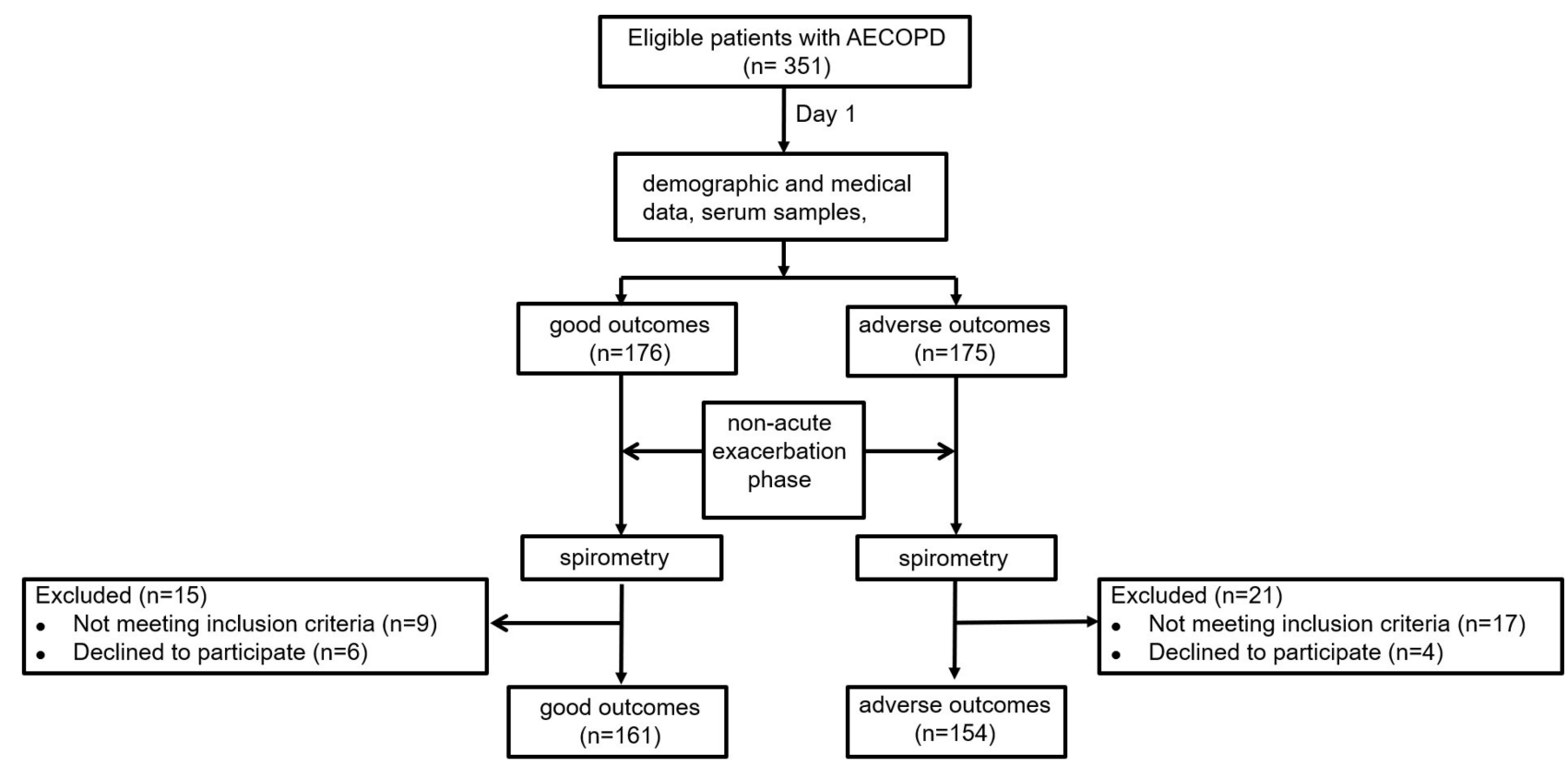

Figure I Flow diagram of patients with AECOPD.

was evaluated by the modified British Medical Research Council (mMRC) scale.

\section{Spirometry Measurements}

Spirometry measurement was based on the American Thoracic Society/European Respiratory Association guidelines. ${ }^{9}$ Data were collected with 6 months prior to enrolment (during the stable phase) or 3 months after AECOPD. Classification of COPD severity followed the GOLD diagnostic criteria. ${ }^{4}$

\section{Sample Collection}

Venous blood samples were obtained from the cubital vein of all the subjects within 3 hours of admission and were centrifuged immediately at $3000 \mathrm{rpm}$ for $15 \mathrm{~min}$ at $4^{\circ} \mathrm{C}$. Subsequently, the plasma and serum samples were stored at $-80^{\circ} \mathrm{C}$ until analysis. The concentration of serum sIL-2R was analysed using a chemiluminescence immunoassay (Siemens, Erlangen, Germany). All the samples from each patient were measured in the same assay to reduce inter-assay variability.

\section{Statistical Analysis}

We calculated the frequency and percentage for categorical variables and mean \pm standard deviation for normal continuous variables or median (1st and 3rd quartiles) for nonnormal distributed continuous variables. To explore the possible relationship of sIL-2R with AECOPD, we classified the participants into three groups according to the tertile of
SIL-2R. Categorical variables in different sIL-2R groups were compared by using the chi-square test or Fisher's exact test. Continuous variables were compared using oneway analysis of variance. Comparisons of parameters with skewed distributions used the Wilcoxon test. Pearson's correlation coefficient was used to analyse the correlation between serum sIL-2R concentration and other variables related with adverse outcomes of AECOPD. Multivariable logistic regression models were used to calculate the odds ratio (OR) $(95 \%$ confidence interval $[\mathrm{CI}])$ of AECOPD after adjusted for potential confounders. We conducted three models: crude model, model adjusted for age, gender, smoking status, BMI and CRP; and model adjusted for age, gender, smoking status, BMI, CRP, history of congestive heart disease, chronic kidney failure, hypertension and diabetes. The receiver operating characteristic (ROC) curve was used to show the predictive ability of sIL-2R for adverse outcomes of AECOPD. SAS software (version 9.4; SAS Institute) was used for data analysis. $P$-value $<0.05$ for twotailed tests was considered statistically significant.

\section{Results}

\section{Comparison of Patients with Good and Adverse Outcomes in Terms of Clinical and Laboratory Variables}

Three hundred and fifteen patients, with an average age of $71.82 \pm 8.44$ years, diagnosed with AECOPD between 
Table I Baseline Clinical and Laboratory Characteristics of Study Population

\begin{tabular}{|c|c|c|c|c|}
\hline Characteristics & Total Population $n=3$ I 5 & Good Outcomes n=|6| & Adverse Outcomes $n=154$ & $P$-value \\
\hline \multicolumn{5}{|l|}{ Demographics } \\
\hline Male, n (\%) & $269(85.4)$ & I42 (88.2) & I 27 (82.47) & 0.1499 \\
\hline Age, year & $71.82 \pm 8.44$ & $71.11 \pm 8.82$ & $72.56 \pm 7.98$ & 0.1251 \\
\hline $\mathrm{BMI}, \mathrm{kg} / \mathrm{m}^{2}$ & $22.49 \pm 3.16$ & $22.67 \pm 3.14$ & $22.29 \pm 3.17$ & 0.2864 \\
\hline Smoking status, n (\%) & & & & 0.6444 \\
\hline Current smoker & $133(42.22)$ & $70(43.48)$ & $63(40.91)$ & \\
\hline Former smoker & $182(57.78)$ & 9I (56.52) & 91 (59.09) & \\
\hline Smoking index, pack-years & $41.04 \pm 24.18$ & $37.26 \pm 23.96$ & $44.98 \pm 23.85$ & 0.0044 \\
\hline \multicolumn{5}{|l|}{ Clinical variables } \\
\hline mMRC, n (\%) & & & & $<0.0001$ \\
\hline mMRC 0-I, n (\%) & $64(20.32)$ & $56(34.78)$ & $8(5.19)$ & \\
\hline mMRC 2, n (\%) & $67(21.27)$ & $47(29.19)$ & $20(12.99)$ & \\
\hline mMRC 3-4, n (\%) & $184(58.4 \mid)$ & $58(36.02)$ & $126(81.82)$ & \\
\hline $\mathrm{FEV}_{1}$, \%pred & $42.17 \pm 17.33$ & $50.52 \pm 17.62$ & $33.44 \pm 11.89$ & $<0.0001$ \\
\hline $\mathrm{FEV}_{1} / \mathrm{FVC}$ & $51.6 \pm 10.52$ & $55.54 \pm 10.11$ & $47.49 \pm 9.32$ & $<0.0001$ \\
\hline GOLD 2017 stages, n (\%) & & & & $<0.0001$ \\
\hline GOLD I-2 & $98(31.11)$ & $84(52.17)$ & 14 (9.09) & \\
\hline GOLD 3-4 & $217(68.89)$ & $77(47.83)$ & $140(90.91)$ & \\
\hline Cerebrovascular disease, n (\%) & $16(5.08)$ & $4(2.48)$ & $12(7.79)$ & 0.0590 \\
\hline Chronic kidney failure, n (\%) & $17(5.4)$ & $5(3.11)$ & $12(7.79)$ & 0.0657 \\
\hline Hypertension, n (\%) & $137(43.49)$ & $62(38.51)$ & $75(48.7)$ & 0.0682 \\
\hline Diabetes, n (\%) & $51(16.19)$ & $23(14.29)$ & $28(18.18)$ & 0.3481 \\
\hline Congestive heart disease, $\mathrm{n}(\%)$ & $132(4 \mid .9)$ & $53(32.92)$ & $79(5 \mid .3)$ & 0.0010 \\
\hline Frequent COPD exacerbation, n (\%) & $156(49.52)$ & $49(30.43)$ & $107(69.48)$ & $<0.0001$ \\
\hline \multicolumn{5}{|l|}{ Laboratory variables } \\
\hline $\mathrm{pH}$ & $7.38 \pm 0.06$ & $7.41 \pm 0.04$ & $7.36 \pm 0.07$ & $<0.0001$ \\
\hline $\mathrm{PaCO}_{2}, \mathrm{mmHg}$ & $54.53 \pm 19.7$ & $42.19 \pm 7.47$ & $67.44 \pm 20.24$ & $<0.0001$ \\
\hline $\mathrm{PaO}_{2} / \mathrm{FiO}_{2}$ & $239.20 \pm 54.51$ & $256.95 \pm 44.44$ & $220.65 \pm 57.91$ & $<0.0001$ \\
\hline WBC, $10^{9} / \mathrm{L}$ & $8.3(6.3,11.3)$ & $8.2(6,11.1)$ & $8.6(6.8,11.3)$ & 0.1916 \\
\hline CRP, mg/L & $31(8,85)$ & $28(8,79)$ & $37.5(9,88)$ & 0.1591 \\
\hline PCT, ng/mL & $0.06(0.04,0.14)$ & $0.06(0.04,0.1)$ & $0.08(0.05,0.25)$ & 0.0085 \\
\hline $\mathrm{ESR}, \mathrm{mm} / \mathrm{h}$ & $34(17,57)$ & $33(17,54)$ & $35(18,62)$ & 0.4551 \\
\hline IL-8, pg/mL & $28.4(16.5,53.1)$ & $23.5(14,48)$ & $33.5(20,53.9)$ & 0.0036 \\
\hline IL-6, pg/mL & $14.59(6.91,24.17)$ & $12.5(5,19.5)$ & $17.36(8.9,27.2)$ & 0.0006 \\
\hline IL-I0, pg/mL & $5(5,5.5)$ & $5(5,5.0)$ & $5(5,6.2)$ & 0.0066 \\
\hline
\end{tabular}

(Continued) 
Table I (Continued).

\begin{tabular}{|l|c|c|c|c|}
\hline Characteristics & Total Population $\mathbf{n = 3 ~ I 5 ~}$ & Good Outcomes $\mathbf{n = 1 6 I}$ & Adverse Outcomes $\mathbf{n =}$ I54 & $\boldsymbol{P}$-value \\
\hline TNF- $\alpha, \mathrm{pg} / \mathrm{mL}$ & $18.4(1 \mathrm{I} .5,32.4)$ & $16.7(9.86,28.7)$ & $22.8(I 4.2,35.7)$ & 0.001 \\
\hline sIL-2R, U/mL & $813(550,1096)$ & $688(472,886)$ & $927(679,1279)$ & $<0.0001$ \\
\hline
\end{tabular}

Note: Data are shown as $\mathrm{n}(\%)$, mean \pm standard deviation (SD) or median (interquartile range).

Abbreviations: GOLD, Global Initiative for Chronic Obstructive Lung Disease; COPD, chronic obstructive pulmonary disease; BMI, body mass index; Smoking index,

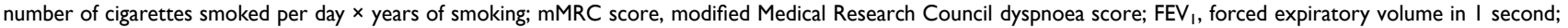
$\mathrm{FEV}_{\mathrm{I}} / \mathrm{FVC}$, forced expiratory volume in I second/force Vital Capacity; WBC, white blood cells; CRP, C-reactive protein; PCT, procalcitonin; ESR, erythrocyte sedimentation rate; IL, interleukin; TNF- $\alpha$,tumor necrosis factor- $\alpha$; sIL-2R, soluble interleukin-2 receptor.

December 2017 and June 2020 were recruited to the observation group, of whom 161 and 154 had good and adverse outcomes, respectively. Patients with adverse outcomes had a higher SI, more severe dyspnoea, significantly lower $\mathrm{FEV}_{1} \%$ pred (\%pred) and $\mathrm{FEV}_{1} / \mathrm{FVC}$ ratio, higher GOLD stage, and more frequent exacerbations within the previous year than patients with good outcomes (Table 1).

As shown in Table 1, the signs of respiratory failure at admission in terms of lower $\mathrm{pH}$, lower ratio of partial arterial oxygen pressure to the fraction of inspired oxygen $\left(\mathrm{PaO}_{2} / \mathrm{FiO}_{2}\right)$, and higher partial arterial carbon dioxide pressure $\left(\mathrm{PaCO}_{2}\right)$ were associated with adverse outcomes ( $p<0.001, p<0.001$, and $p<0.001$, respectively). Serum procalcitonin $(p=0.0085)$, interleukin-6 (IL-6) $(p=$ 0.0006), interleukin-8 (IL-8) $(p=0.0036)$, interleukin-10 (IL-10) $(p=0.0066)$, tumour necrosis factor- $\alpha(\mathrm{TNF}-\alpha)$ $(p=0.001)$, and sIL-2R $(p<0.0001)$ were higher in the adverse outcomes group than in the good outcomes group.

\section{Correlation of Serum sIL-2R with mMRC Score}

Patients were divided into three groups according to the tertile of the serum concentration of sIL-2R at admission: group 1, < $619 \mathrm{U} / \mathrm{mL}$; group 2, 619-947 U/mL; and group $3,>948 \mathrm{U} / \mathrm{mL}$. As shown in Table 2, in the group with a high concentration of sIL-2R, the number of patients with an mMRC score of 3-4 was more than those with an mMRC score of $0-1$ and $2(p=0.0002)$. Subgroup analysis (Table 3) showed that the risk of adverse outcomes in patients with AECOPD increased gradually with the increase of sIL-2R concentration in either the mMRC score of $0-1,2$, or 3-4 group. By adjusting the analysis, the statistical results showed that serum sIL-2R concentration was more closely associated with adverse outcomes of AECOPD in the mMRC score of 3-4 group. In the mMRC score of $0-1,2$, and 3-4 groups, serum sIL-2R concentration was higher in patients with adverse outcomes than in those with good outcomes (Table 4, Figure 2A).

\section{Correlation of Serum slL-2R with GOLD Stages}

Subgroup analysis (Table 3) showed that the risk of adverse outcomes in patients with AECOPD increased gradually with the increase of sIL-2R concentration in either the GOLD 1-2 or GOLD 3-4 group. By adjusting the analysis, the statistical results showed that concentration of serum sIL-2R was more closely associated with adverse outcomes of AECOPD in the GOLD 1-2 group. In both GOLD 1-2 and GOLD 3-4 groups, the serum sIL-2R concentration was higher in patients with adverse outcomes than in those with good outcomes (Table 4, Figure 2B).

\section{Correlation of Serum sIL-2R with Frequent Exacerbation}

As shown in Table 3, the risk of adverse outcomes of AECOPD increased gradually with the increase of sIL$2 \mathrm{R}$ concentration in either the non-frequent or frequent exacerbation group. By adjusting analysis, the statistical results showed that serum sIL-2R concentration was more closely associated with adverse outcomes of AECOPD in the frequent exacerbation group. In both the frequent and non-frequent exacerbation groups, the concentration of sIL-2R was higher in patients with adverse outcomes than in those with good outcomes (Table 4, Figure 2C).

\section{Correlation of Serum sIL-2R with Smoking Status}

As shown in Table 3, the risk of adverse outcomes in patients with AECOPD increased gradually with the increase of sIL-2R concentration in patients in the 
Table 2 Clinical and Laboratory Characteristics According to the Tertile of sIL-2R

\begin{tabular}{|c|c|c|c|c|}
\hline \multirow[t]{2}{*}{ Characteristics } & \multicolumn{3}{|c|}{ sIL-2R } & \multirow[t]{2}{*}{$P$-value } \\
\hline & Tertile I $<619 \mathrm{U} / \mathrm{mL}$ & Tertile $2619-947 \mathrm{U} / \mathrm{mL}$ & Tertile $3 \geq 948 \mathrm{U} / \mathrm{mL}$ & \\
\hline No. of participants & 103 & 104 & 108 & \\
\hline \multicolumn{5}{|l|}{ Demographics } \\
\hline Male, n (\%) & 91 (88.35) & $86(82.69)$ & $92(85.19)$ & 0.5244 \\
\hline Age, year & $68.8 \pm 7.63$ & $72.48 \pm 8.6$ & $74.06 \pm 8.24$ & $<0.0001$ \\
\hline $\mathrm{BMI}, \mathrm{kg} / \mathrm{m}^{2}$ & $22.96 \pm 3.47$ & $22.49 \pm 3.01$ & $22.04 \pm 2.93$ & 0.1041 \\
\hline Smoking status, n (\%) & & & & 0.0919 \\
\hline Current smoker & $48(46.6)$ & $47(45.19)$ & $38(35.19)$ & \\
\hline Former smoker & $55(53.4)$ & $57(54.8 \mathrm{I})$ & $70(64.8 I)$ & \\
\hline Smoking index, pack-years & $42.39 \pm 25.6$ & $39.31 \pm 19.72$ & $4 I .4 I \pm 26.68$ & 0.6455 \\
\hline \multicolumn{5}{|l|}{ Clinical variables } \\
\hline mMRC, n (\%) & & & & 0.0002 \\
\hline mMRC 0-I, n (\%) & $30(29.13)$ & $22(2 \mid .15)$ & $12(I 1.11)$ & \\
\hline mMRC 2, n (\%) & $24(23.3)$ & $24(23.08)$ & $19(17.59)$ & \\
\hline mMRC 3-4, n (\%) & $49(47.57)$ & $58(55.77)$ & $77(71.3)$ & \\
\hline $\mathrm{FEV}_{1}$, \%pred & $45.38 \pm 18.72$ & $42.09 \pm 16.97$ & $39.19 \pm 15.84$ & 0.0340 \\
\hline $\mathrm{FEV}_{1} / \mathrm{FVC}$ & $52.84 \pm 10.77$ & $52.84 \pm 10.57$ & $49.23 \pm 9.89$ & 0.0147 \\
\hline GOLD 2017 stages, n (\%) & & & & 0.2619 \\
\hline GOLD I-2 & $34(33.01)$ & $36(34.62)$ & $28(25.93)$ & \\
\hline GOLD 3-4 & 69 (66.99) & $68(65.38)$ & $80(74.07)$ & \\
\hline Cerebrovascular disease, n (\%) & $3(2.91)$ & $4(3.85)$ & $9(8.33)$ & 0.0720 \\
\hline Chronic kidney failure, n (\%) & $3(2.91)$ & $3(2.88)$ & II (10.19) & 0.0187 \\
\hline Hypertension, n (\%) & $42(40.78)$ & $4 \mathrm{I}(39.42)$ & $54(50)$ & 0.1730 \\
\hline Diabetes, n (\%) & $15(14.56)$ & $17(16.35)$ & $19(17.59)$ & 0.5516 \\
\hline Congestive heart disease, $\mathrm{n}(\%)$ & $27(26.21)$ & $48(46.15)$ & $57(52.78)$ & 0.0001 \\
\hline Frequent COPD exacerbation, $\mathrm{n}$ (\%) & $48(46.6)$ & $47(45.19)$ & $6 \mathrm{I}(56.48)$ & 0.1171 \\
\hline \multicolumn{5}{|l|}{ Laboratory variables } \\
\hline $\mathrm{pH}$ & $7.38 \pm 0.05$ & $7.39 \pm 0.06$ & $7.37 \pm 0.08$ & 0.1194 \\
\hline $\mathrm{PaCO}_{2}, \mathrm{mmHg}$ & $52.25 \pm 18.12$ & $53.02 \pm 20.32$ & $58.17 \pm 20.19$ & 0.0579 \\
\hline $\mathrm{PaO}_{2} / \mathrm{FiO}_{2}$ & $24 \mid .6 I \pm 50.31$ & $239.21 \pm 54.24$ & $236.9 \pm 58.84$ & 0.8222 \\
\hline WBC, $10^{9} / \mathrm{L}$ & $7.7(5.9,9.6)$ & $8(6.2,10.85)$ & $10(7.2,12.4)$ & 0.0005 \\
\hline CRP, mg/L & $9(5,29)$ & $46.5(10,87)$ & $63.5(26,103)$ & $<0.0001$ \\
\hline PCT, ng/mL & $0.05(0.03,0.07)$ & $0.07(0.04,0.15)$ & $0.09(0.05,0.27)$ & $<0.0001$ \\
\hline $\mathrm{ESR}, \mathrm{mm} / \mathrm{h}$ & $24(\mathrm{II}, 40)$ & $36(18,56.5)$ & $41(23,66.5)$ & $<0.0001$ \\
\hline IL-8, pg/mL & $23.2(12.6,53.7)$ & $28.5(16.95,48.1)$ & $30.4(19.6,60)$ & 0.1195 \\
\hline $\mathrm{IL}-6, \mathrm{pg} / \mathrm{mL}$ & $5.88(2.94,10.5)$ & $16.14(10.6,22.4)$ & $23.93(15.99,33.3)$ & $<0.0001$ \\
\hline IL-10, pg/mL & $5(5,5)$ & $5(5,5.5 I)$ & $5(5,7.67)$ & $<0.0001$ \\
\hline TNF- $\alpha, p g / m L$ & I4.3 (7.98,29.1) & I6.5 (I I.0,27.8) & $21.55(16.3,33.45)$ & $<0.0001$ \\
\hline
\end{tabular}

Notes: Data are shown as $\mathrm{n}(\%)$, mean \pm standard deviation (SD) or median (interquartile range). Bold font indicates $P<0.05$.

Abbreviations: GOLD, Global Initiative for Chronic Obstructive Lung Disease; COPD, chronic obstructive pulmonary disease; BMI, body mass index; Smoking index, number of cigarettes smoked per day $\times$ years of smoking; mMRC score, modified Medical Research Council dyspnoea score; FEV 1 , forced expiratory volume in I second; FEV / FVC, forced expiratory volume in I second/force Vital Capacity; WBC, white blood cells; CRP, C-reactive protein; PCT, procalcitonin; ESR, erythrocyte sedimentation rate; IL, interleukin; TNF- $\alpha$,tumor necrosis factor- $\alpha$; sIL-2R, soluble interleukin-2 receptor. 
Table 3 Association Between sIL-2R and Adverse Outcomes in Overall Patients with AECOPD and Subgroups Stratified by Related Factors

\begin{tabular}{|c|c|c|c|c|}
\hline $\begin{array}{l}\text { Characteristics or } \\
\text { Subgroups }\end{array}$ & $\begin{array}{c}\text { OR of Adverse } \\
\text { Outcomes }(95 \% \mathrm{Cl})\end{array}$ & $\begin{array}{l}\text { Adjusted OR of Adverse } \\
\text { Outcomes }(95 \% \mathrm{CI}) *\end{array}$ & $\begin{array}{l}\text { Adjusted OR of Adverse } \\
\text { Outcomes }(95 \% \mathrm{Cl})^{\#}\end{array}$ & $\begin{array}{l}\text { P-value for } \\
\text { Trend }\end{array}$ \\
\hline \multicolumn{5}{|l|}{ Overall patients } \\
\hline $\begin{array}{l}\text { sIL-2R, per } \mathbf{1 0 0 U} \text { / } \\
\mathbf{m L} \\
\text { Tertile I } \\
\text { Tertile } 2 \\
\text { Tertile } 3\end{array}$ & $\begin{array}{c}\text { I.2I }(1.13,1.30) \\
\text { Referent } \\
1.90(1.08,3.36) \\
4.83(2.70,8.65)\end{array}$ & $\begin{array}{c}1.24(1.15,1.34) \\
\text { Referent } \\
2.02(1.09,3.72) \\
5.24(2.70,10.16)\end{array}$ & $\begin{array}{c}1.22(1.13,1.32) \\
\text { Referent } \\
1.94(1.04,3.63) \\
4.73(2.41,9.27)\end{array}$ & 0.0001 \\
\hline \multicolumn{5}{|l|}{ mMCR subgroups } \\
\hline \multicolumn{5}{|l|}{$\begin{array}{l}\text { Patients with } \\
\text { mMCR 0-I }\end{array}$} \\
\hline $\begin{array}{l}\text { sIL-2R, per } 100 \mathrm{U} / \mathrm{mL} \\
\text { Tertile I } \\
\text { Tertile } 2 \\
\text { Tertile } 3\end{array}$ & $\begin{array}{c}1.26(1.04,1.54) \\
\text { Referent } \\
1.40(0.18,10.79) \\
7.00(1.08,45.44)\end{array}$ & $\begin{array}{c}\text { I.40 }(1.07, \mathrm{I} .83) \\
\text { Referent } \\
1.27(0.33,4.89) \\
3.42(0.90,12.99)\end{array}$ & $\begin{array}{c}1.43(1.07,1.90) \\
\text { Referent } \\
2.13(0.97,4.70) \\
3.66(1.67,8.03)\end{array}$ & 0.0193 \\
\hline \multicolumn{5}{|l|}{$\begin{array}{l}\text { Patients with } \\
\text { mMCR } 2\end{array}$} \\
\hline $\begin{array}{l}\text { sIL-2R, per } 100 \mathrm{U} / \mathrm{mL} \\
\text { Tertile I } \\
\text { Tertile } 2 \\
\text { Tertile } 3\end{array}$ & $\begin{array}{c}\text { I.12 }(0.99, \text { I.27) } \\
\text { Referent } \\
1.25(0.27,5.87) \\
5.50(0.90,33.8 \mathrm{I})\end{array}$ & $\begin{array}{c}\text { I.I7 }(0.99, \text { I.39) } \\
\text { Referent } \\
3.44(1.35,8.79) \\
5.89(2.24,15.51)\end{array}$ & $\begin{array}{c}\text { I.2I }(1.00,1.46) \\
\text { Referent } \\
2.20(0.18,26.48) \\
19.43(1.35,279.79)\end{array}$ & 0.0178 \\
\hline \multicolumn{5}{|c|}{ Patients with mMCR 3-4 } \\
\hline $\begin{array}{l}\text { slL-2R, per } 100 \mathrm{U} / \mathrm{mL} \\
\text { Tertile I } \\
\text { Tertile } 2 \\
\text { Tertile } 3\end{array}$ & $\begin{array}{c}1.21(1.10,1.34) \\
\text { Referent } \\
3.38(1.28,8.96) \\
5.33(1.98,14.41)\end{array}$ & $\begin{array}{c}\text { I.3। }(1.16,1.49) \\
\text { Referent } \\
15.23(0.32,726.91) \\
90.28(1.45,1000)\end{array}$ & $\begin{array}{c}1.30(1.14,1.48) \\
\text { Referent } \\
0.73(0.11,4.72) \\
21.03(1.68,263.65)\end{array}$ & 0.0124 \\
\hline \multicolumn{5}{|c|}{ Patients with GOLD stage I-2 } \\
\hline $\begin{array}{l}\text { sIL-2R, per } 100 \mathrm{U} / \mathrm{mL} \\
\text { Tertile I } \\
\text { Tertile } 2 \\
\text { Tertile } 3\end{array}$ & $\begin{array}{c}\text { I.24 }(\mathrm{I} .07, \mathrm{I} .43) \\
\text { Referent } \\
5.32(0.59,48.13) \\
13.20(1.54, \mathrm{I} \mid \mathrm{I} .48)\end{array}$ & $\begin{array}{c}\text { I.30 }(\mathrm{I} .09, \mathrm{I} .55) \\
\text { Referent } \\
4.85(0.47,50.48) \\
17.28(1.62,184.05)\end{array}$ & $\begin{array}{c}\text { I.30 }(1.06,1.60) \\
\text { Referent } \\
3.46(0.28,42.13) \\
19.21(1.42,260.55)\end{array}$ & 0.0102 \\
\hline \multicolumn{5}{|c|}{ Patients with GOLD stage 3-4 } \\
\hline $\begin{array}{l}\text { sIL-2R, per } 100 \mathrm{U} / \mathrm{mL} \\
\text { Tertile I } \\
\text { Tertile } 2 \\
\text { Tertile } 3\end{array}$ & $\begin{array}{c}1.29(1.17,1.43) \\
\text { Referent } \\
2.11(1.06,4.18) \\
5.78(2.74,12.19)\end{array}$ & $\begin{array}{c}1.33(1.19,1.49) \\
\text { Referent } \\
2.30(1.09,4.81) \\
6.10(2.63,14.18)\end{array}$ & $\begin{array}{c}1.33(\mathrm{I} .18, \mathrm{I} .49) \\
\text { Referent } \\
2.4 \mathrm{I}(\mathrm{I} .13,5.1 \mathrm{I}) \\
5.88(2.50,13.85)\end{array}$ & 0.0043 \\
\hline \multicolumn{5}{|c|}{ Non-Frequent AECOPD patients } \\
\hline $\begin{array}{l}\text { sIL-2R, per } 100 \mathrm{U} / \mathrm{mL} \\
\text { Tertile I } \\
\text { Tertile } 2 \\
\text { Tertile } 3\end{array}$ & $\begin{array}{c}\text { I.2I }(1.09,1.33) \\
\text { Referent } \\
2.24(0.87,5.79) \\
5.51(2.14,14.16)\end{array}$ & $\begin{array}{c}\text { I.24 }(\mathrm{I} . \mathrm{II}, \mathrm{I} .38) \\
\text { Referent } \\
2.42(0.87,6.73) \\
6.27(2.20,17.84)\end{array}$ & $\begin{array}{c}1.22(1.09,1.37) \\
\text { Referent } \\
2.23(0.78,6.37) \\
4.86(1.62,14.53)\end{array}$ & 0.0244 \\
\hline
\end{tabular}


Table 3 (Continued).

\begin{tabular}{|c|c|c|c|c|}
\hline $\begin{array}{l}\text { Characteristics or } \\
\text { Subgroups }\end{array}$ & $\begin{array}{c}\text { OR of Adverse } \\
\text { Outcomes }(95 \% \mathrm{Cl})\end{array}$ & $\begin{array}{l}\text { Adjusted OR of Adverse } \\
\text { Outcomes }(95 \% \mathrm{Cl})^{*}\end{array}$ & $\begin{array}{l}\text { Adjusted OR of Adverse } \\
\text { Outcomes }(95 \% \mathrm{Cl})^{\#}\end{array}$ & $\begin{array}{l}\text { P-value for } \\
\text { Trend }\end{array}$ \\
\hline $\begin{array}{l}\text { sIL-2R, per } 100 \mathrm{U} / \mathrm{mL} \\
\text { Tertile I } \\
\text { Tertile } 2 \\
\text { Tertile } 3\end{array}$ & $\begin{array}{c}1.23(1.1 \mathrm{I}, \mathrm{I} .37) \\
\text { Referent } \\
2.13(0.93,4.91) \\
5.10(2.11,12.33)\end{array}$ & $\begin{array}{c}1.39(1.19,1.62) \\
\text { Referent } \\
3.43(1.26,9.29) \\
9.69(2.95,31.83)\end{array}$ & $\begin{array}{c}\text { I.43 }(1.20,1.69) \\
\text { Referent } \\
4.07(1.42,11.66) \\
12.90(3.48,47.72)\end{array}$ & 0.0015 \\
\hline \multicolumn{5}{|l|}{ Former smoker } \\
\hline $\begin{array}{l}\text { sIL-2R, per } 100 \mathrm{U} / \mathrm{mL} \\
\text { Tertile I } \\
\text { Tertile } 2 \\
\text { Tertile } 3\end{array}$ & $\begin{array}{l}\text { I.I7 }(1.08,1.26) \\
\quad \text { Referent } \\
1.98(0.92,4.27) \\
3.70(1.76,7.80)\end{array}$ & $\begin{array}{c}1.20(1.09,1.31) \\
\text { Referent } \\
2.40(1.03,5.55) \\
4.42(1.85,10.53)\end{array}$ & $\begin{array}{c}\text { I.I8 }(1.08,1.30) \\
\text { Referent } \\
2.41(1.02,5.73) \\
4.23(1.74,10.28)\end{array}$ & 0.0077 \\
\hline \multicolumn{5}{|l|}{ Current smoker } \\
\hline $\begin{array}{l}\text { sIL-2R, per } 100 \mathrm{U} / \mathrm{mL} \\
\text { Tertile I } \\
\text { Tertile } 2 \\
\text { Tertile } 3\end{array}$ & $\begin{array}{c}1.31(1.16,1.49) \\
\text { Referent } \\
1.80(0.77,4.21) \\
7.83(2.96,20.7)\end{array}$ & $\begin{array}{l}\text { I.34 }(1.16,1.54) \\
\quad \text { Referent } \\
1.73(0.67,4.43) \\
8.51(2.83,25.6)\end{array}$ & $\begin{array}{c}\text { I.36 }(1.16,1.60) \\
\text { Referent } \\
\text { I.57 }(0.57,4.31) \\
7.29(2.25,23.62)\end{array}$ & 0.0034 \\
\hline \multicolumn{5}{|l|}{ FEV $_{\mathrm{I}}$ \%pred > 40} \\
\hline $\begin{array}{l}\text { sIL-2R, per } 100 \mathrm{U} / \mathrm{mL} \\
\text { Tertile I } \\
\text { Tertile } 2 \\
\text { Tertile } 3\end{array}$ & $\begin{array}{c}1.19(1.08,1.32) \\
\text { Referent } \\
2.41(0.87,6.64) \\
4.57(1.7,12.33)\end{array}$ & $\begin{array}{c}1.24(1.10,1.39) \\
\text { Referent } \\
2.73(0.89,8.36) \\
5.25(1.68,16.43)\end{array}$ & $\begin{array}{c}\text { I.24 }(1.10,1.40) \\
\text { Referent } \\
\text { I.59 }(0.62,4.07) \\
6.63(2.03,21.65)\end{array}$ & 0.0020 \\
\hline \multicolumn{5}{|l|}{ FEV $_{1}, \%$ pred $\leq \mathbf{4 0}$} \\
\hline $\begin{array}{l}\text { sIL-2R, per } 100 \mathrm{U} / \mathrm{mL} \\
\text { Tertile I } \\
\text { Tertile } 2 \\
\text { Tertile } 3\end{array}$ & $\begin{array}{c}\mathrm{I} .3(\mathrm{I} .15, \mathrm{I} .46) \\
\text { Referent } \\
\mathrm{I.70}(0.77,3.75) \\
7.36(2.79,19.39)\end{array}$ & $\begin{array}{c}\text { I.32 }(1.14, \text { I.52) } \\
\text { Referent } \\
1.60(0.65,3.90) \\
6.84(2.23,21.03)\end{array}$ & $\begin{array}{c}\text { I.32 }(1.13,1.53) \\
\text { Referent } \\
\text { I.59 }(0.62,4.07) \\
6.63(2.03,21.65)\end{array}$ & 0.0363 \\
\hline \multicolumn{5}{|l|}{$F V_{1} / F V C>45$} \\
\hline $\begin{array}{l}\text { slL-2R, per } 100 \mathrm{U} / \mathrm{mL} \\
\text { Tertile I } \\
\text { Tertile } 2 \\
\text { Tertile } 3\end{array}$ & $\begin{array}{c}1.16(1.08,1.26) \\
\text { Referent } \\
1.83(0.92,3.63) \\
3.27(1.61,6.62)\end{array}$ & $\begin{array}{c}1.18(1.08,1.28) \\
\text { Referent } \\
1.94(0.91,4.13) \\
3.32(1.49,7.36)\end{array}$ & $\begin{array}{c}1.17(1.08,1.28) \\
\text { Referent } \\
1.84(0.86,3.95) \\
3.13(1.39,7.03)\end{array}$ & 0.0064 \\
\hline \multicolumn{5}{|l|}{$\mathrm{FEV}_{\mathrm{I}} / \mathrm{FVC} \leq \mathbf{4 5}$} \\
\hline $\begin{array}{l}\text { sIL-2R, per } 100 \mathrm{U} / \mathrm{mL} \\
\text { Tertile I } \\
\text { Tertile } 2 \\
\text { Tertile } 3\end{array}$ & $\begin{array}{l}1.38(1.17,1.62) \\
\quad \text { Referent } \\
2.25(0.76,6.65) \\
12.2(3.39,43.8)\end{array}$ & $\begin{array}{l}\text { I.49 }(I .2 I, I .83) \\
\quad \text { Referent } \\
2.49(0.75,8.26) \\
19.5(3.94,97.1)\end{array}$ & $\begin{array}{c}1.53(1.20,1.95) \\
\quad \text { Referent } \\
3.08(0.71,13.3) \\
23.0(3.47,152)\end{array}$ & 0.0113 \\
\hline
\end{tabular}

Notes: *Adjusted for age, gender, smoking status, BMI and CRP; ${ }^{\#}$ Adjusted for age, gender, smoking status, BMI, CRP, history of congestive heart disease, chronic kidney failure, hypertension and diabetes.

Abbreviations: AECOPD, acute exacerbation of chronic obstructive pulmonary disease; OR, odds ratio; Cl, confidence interval; slL-2R, soluble interleukin-2 receptor; mMRC score, modified Medical Research Council dyspnoea score; GOLD, Global Initiative for Chronic Obstructive Lung Disease; FEV I second; FEV/FVC, forced expiratory volume in I second/force Vital Capacity.

current or former smoker groups. By adjusting the analysis, the statistical results showed that concentration of serum sIL-2R was more closely associated with adverse outcomes of AECOPD in patients in the current smoker group. In both the current and former smoker groups, the concentration of serum sIL-2R was higher in patients with adverse outcomes than in those with good outcomes (Table 4, Figure 2D). 
Table 4 Relationship Between Clinical Parameters and the Serum Concentration of sIL-2R in Each Group

\begin{tabular}{|c|c|c|c|}
\hline Variable & $\begin{array}{c}\text { Good } \\
\text { Outcomes } \\
\text { Group }\end{array}$ & $\begin{array}{c}\text { Adverse } \\
\text { Outcomes } \\
\text { Group }\end{array}$ & $P$-value \\
\hline mMRC 0-I & $648.26 \pm 247.41$ & $869.32 \pm 321.79$ & $<0.05$ \\
\hline $\mathrm{mMRC} 2$ & $667.8 \pm 241.92$ & $902.86 \pm 395.41$ & $<0.05$ \\
\hline mMRC 3-4 & $692.17 \pm 323.04$ & $1179.49 \pm 411.26 *$ & $<0.001$ \\
\hline GOLD I-2 & $606.48 \pm 213.14$ & $904.66 \pm 414.47^{\#}$ & $<0.001$ \\
\hline GOLD 3-4 & $784.57 \pm 382.09$ & $1126.24 \pm 433.68$ & $<0.001$ \\
\hline $\begin{array}{l}\text { Non-Frequent } \\
\text { AECOPD }\end{array}$ & $661.14 \pm 217.96$ & $912.38 \pm 389.16$ & $<0.05$ \\
\hline $\begin{array}{l}\text { Frequent } \\
\text { AECOPD }\end{array}$ & $720.66 \pm 349.13$ & $1090.54 \pm 416.12$ & $<0.001$ \\
\hline $\begin{array}{l}\text { Former } \\
\text { smoker }\end{array}$ & $670.13 \pm 264.72$ & $936.63 \pm 437.15$ & $<0.05$ \\
\hline $\begin{array}{l}\text { Current } \\
\text { smoker }\end{array}$ & $720.4 \pm 308.15$ & || $84.26 \pm 424.3 \mid$ & $<0.001$ \\
\hline 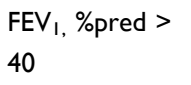 & $634.51 \pm 243.9$ & $9|7.7| \pm 458.81$ & $<0.001$ \\
\hline $\begin{array}{l}\mathrm{FEV}_{1}, \% \text { pred } \leq \\
40\end{array}$ & $746.27 \pm 313.62$ & || $20.06 \pm 4 \mid 2.73$ & $<0.001$ \\
\hline $\mathrm{FEV}_{\mathrm{I}} / \mathrm{FVC}>45$ & $637.08 \pm 217.14$ & $872.33 \pm 321.64$ & $<0.05$ \\
\hline $\mathrm{FEV}_{\mathrm{l}} / \mathrm{FVC} \leq 45$ & $763.46 \pm 362.91$ & $1210.51 \pm 427.44^{\$}$ & $<0.001$ \\
\hline
\end{tabular}

Notes: Data are shown as mean \pm standard deviation (SD); *Serum concentration of sIL-2R was higher in patients with mMRC 3-4 than in those with mMRC $0-1$ in adverse outcomes group $(P<0.05)$; ${ }^{\#}$ Serum concentration of slL-2R was higher in patients of adverse outcomes group than in those of good outcomes group in GOLD I-2 $(P<0.05)$; ${ }^{\$}$ Serum concentration of sIL-2R was higher in patients with $\mathrm{FEV} / \mathrm{FVC} \leq 45$ than in those with $\mathrm{FEV}_{\mathrm{l}} / \mathrm{FVC}>45$ in adverse outcomes group $(P<0.05)$.

Abbreviations: sIL-2R, soluble interleukin-2 receptor; mMRC score, modified Medical Research Council dyspnoea score; GOLD, Global Initiative for Chronic Obstructive Lung Disease; AECOPD, acute exacerbation of chronic obstructive pulmonary disease; $\mathrm{FEV}_{1}$, forced expiratory volume in I second; $F E V_{1} / F V C$, forced expiratory volume in I second/force vital capacity.

\section{Correlation of Serum sIL-2R with FEV,\% pred and $\mathrm{FEV}_{\mathrm{I}} / \mathrm{FVC}$}

Table 2 shows that with an increase in the sIL-2R concentration, the $\mathrm{FEV}_{1}$ \%pred and $\mathrm{FEV}_{1} / \mathrm{FVC}$ ratio decreased gradually $(p<0.05$ and $p<0.05$, respectively). Subgroup analysis (Table 3) showed that an increase in the sIL-2R concentration in both high and low $\mathrm{FEV}_{1} \%$ pred groups, the risk of developing adverse outcomes of AECOPD significantly increased. Similarly, with the increase of sIL-2R concentration in both the high and low $\mathrm{FEV}_{1} / \mathrm{FVC}$ groups, the risk of developing adverse outcomes of AECOPD significantly increased. By adjusting the analysis, the statistical results showed that concentration of serum sIL-2R was more closely associated with adverse outcomes of AECOPD in the low $\mathrm{FEV}_{1}$ \%pred and low $\mathrm{FEV}_{1} / \mathrm{FVC}$ groups.
Statistical results showed (Table 4, Figure 3A) that in both high and low $\mathrm{FEV}_{1}$ \%pred groups, the serum sIL-2R concentration was higher in patients with adverse outcomes than in those with good outcomes. Additionally, in both the high and low $\mathrm{FEV}_{1} / \mathrm{FVC}$ groups, the concentration of serum sIL-2R was higher in patients with adverse outcomes than in those with good outcomes (Table 4, Figure 3B).

\section{Correlation of Serum sIL-2R with Other Laboratory Variables}

As shown in Table 5, sIL-2R was positively correlated to $\mathrm{PaCO}_{2}$, whole blood leukocyte counts (WBC), C-reactive protein (CRP), erythrocyte sedimentation rate, and IL-6, IL-10, and TNF- $\alpha$ levels and negatively correlated with serum $\mathrm{pH}$ and $\mathrm{PaO}_{2} / \mathrm{FiO}_{2}$.

\section{Determination of Serum sIL-2R Concentration Contributes to the Differential Diagnosis of Adverse Outcomes in AECOPD}

Table 3 shows that as sIL-2R concentration increased, the association with adverse outcomes of AECOPD became stronger in all the subjects $(\mathrm{OR}=1.21 ; 95 \% \mathrm{CI}, 1.13-1.3$; $p<0.05)$. By adjusting the analysis, the serum sIL-2R concentration was still positively correlated with the adverse outcomes of AECOPD in all the subjects.

The ROC curve analysis indicated that the area under the curve (AUC) of sIL-2R to distinguish adverse outcomes in AECOPD was 0.6887 (95\% CI, 0.6304-0.7470) (Figure 4). With a cut-off value of $860 \mathrm{U} / \mathrm{mL}$, the sensitivity and specificity were $62.0 \%$ and $73.9 \%$, respectively.

\section{Discussion}

COPD is associated with the chronic inflammation of the airways and lung parenchyma, which increases during acute exacerbations and is associated with systemic inflammation. Inflammatory biomarkers can be used to supplement clinical data and determine the health status of patients before, during, and after the occurrence of COPD exacerbation. ${ }^{10,11}$ Over the past decade, various inflammatory biomarkers associated with COPD exacerbation have been investigated. ${ }^{12-14}$ However, whether sIL$2 \mathrm{R}$ is associated with the exacerbation of COPD has not been reported. Our study found that the serum sIL-2R concentration in patients with adverse outcomes of AECOPD was higher than in those with good outcome, 

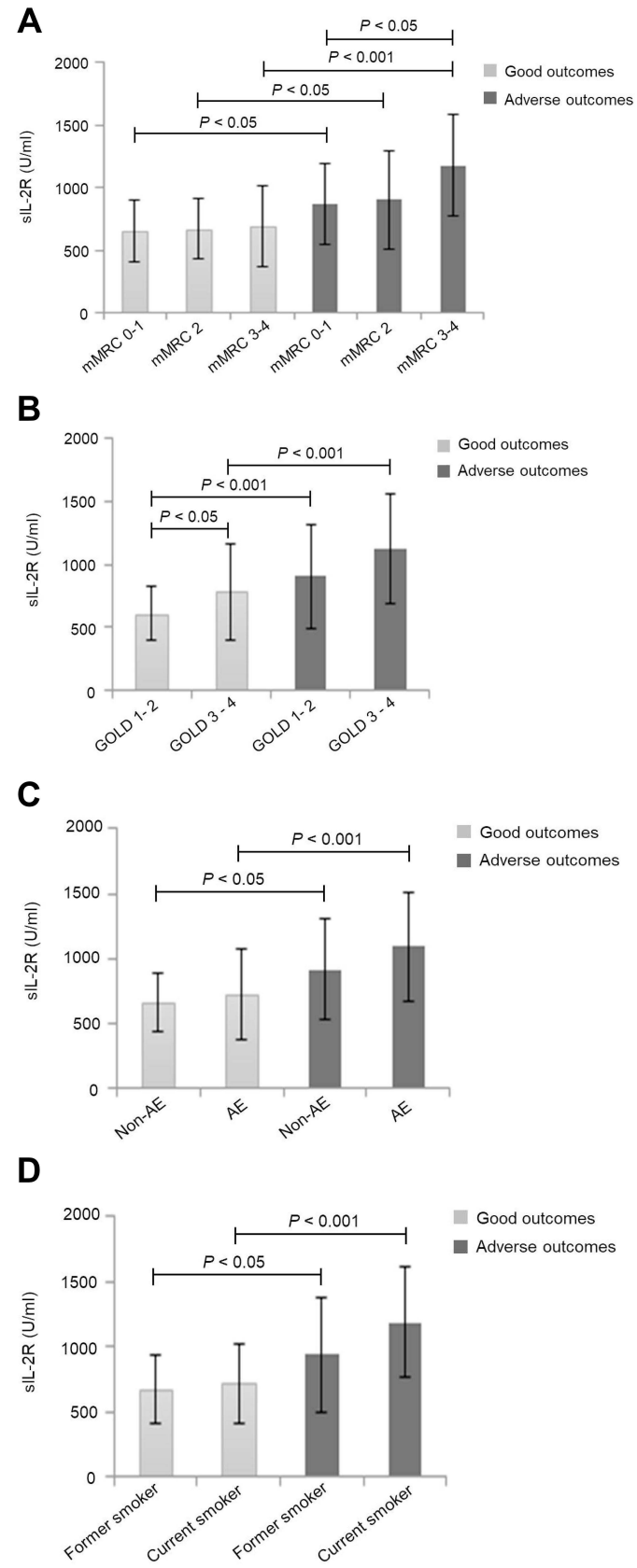

Figure 2 Relationship between clinical parameters and serum concentration of slL$2 R$ in good and adverse outcomes of AECOPD.

Notes: (A) In the mMRC score of $0-1,2$ and 3-4 groups, sIL-2R concentration was higher in patients with adverse outcomes than in those with good outcomes $(P<0.05$, $P<0.05, P<0.00$ I, respectively); Serum sIL-2R concentration was higher in patients with mMRC 3-4 than in those with mMRC $0-1$ in adverse outcomes group $(P<0.05)$; (B) In both GOLD I-2 and GOLD 3-4 groups, sIL-2R concentration was higher in patients with adverse outcomes than in those with good outcomes $(P<0.001, P<0.001$, respectively); Serum sIL-2R concentration was higher in patients of adverse outcomes group than in those of good outcomes group in GOLD I-2 $(P<0.05)$; $(\mathbf{C})$ In both the frequent and non-frequent exacerbation groups, the concentration of sIL-2R was higher in patients with adverse outcomes than in those with good outcomes $(P<0.05, P<0.00$ I, respectively); (D) In both the current and former smoker groups, the concentration of serum sIL-2R was higher in patients with adverse outcomes than in those with good outcomes $(P<0.05, P<0.00 \mathrm{I}$, respectively).

Abbreviations: sIL-2R, soluble interleukin- 2 receptor; $m M R C$ score, modified Medical Research Council dyspnoea score; GOLD, Global Initiative for Chronic Obstructive Lung Disease; AECOPD, acute exacerbation of chronic obstructive pulmonary disease. indicating that sIL-2R may play a potential role in the development of AECOPD.

The sIL-2R comprises of $\alpha$ (CD25), $\beta$ (CD122), and common $\gamma$ (CD132) chains expressing on the surface of $\mathrm{T}$ cells and is released by $\mathrm{T}$ cells in a soluble form as sIL$2 \mathrm{R} .{ }^{15,16}$ Furthermore, sIL-2R is present in vivo, at low levels in the sera of healthy individuals, but are further increased in patients during the acute or aggravated phase of the disease and decreased during the convalescence period or after treatment, ${ }^{17,18}$ such as in patients with cancer; ${ }^{19}$ inflammatory bowel disease $;{ }^{17}$ IgG4-related disease, ${ }^{20}$ autoimmune inflammation, including rheumatoid arthritis; ${ }^{21}$ systemic lupus erythematosus; ${ }^{22}$ sarcoidosis; ${ }^{23}$ and severe asthma. ${ }^{24}$

Cigarette smoke exposure is a significant risk factor for the occurrence and development of a variety of airway diseases. Inflammation caused by cigarette smoke plays a key role in bronchospasm airway remodelling and lung tissue damage. Even after smoking cessation, pulmonary inflammation continues to occur; hence, it is speculated that there are autoimmune factors in COPD. Several studies have found ${ }^{25,26}$ that the increased number of $\mathrm{T}$ cells in the lungs and airways of patients with COPD correlated with disease severity, and the proportion of $\mathrm{T}$ cells in sputum was significantly increased during AECOPD compared to that in the stable phase. ${ }^{27,28}$ Serum sIL-2R expression is increased with T-cell activation. Our study showed that the AECOPD patients with adverse outcomes who still smoked had a significantly higher serum concentration of sIL-2R than those patients with good outcomes, suggesting that cigarette smoke may promote the occurrence and development of COPD by activating T cells.

The lung function test is an indicator of the degree of airflow limitation in patients with COPD. Our study found that serum concentration of sIL-2R in AECOPD was negatively correlated with the rate of decline in $\mathrm{FEV}_{1} \%$ pred and $\mathrm{FEV}_{1} / \mathrm{FVC}$, both in the total population and in the subgroups. Serum sIL-2R concentration in patients with AECOPD at the GOLD 3-4 stage was higher than that in patients at the GOLD 1-2 stage, both in the total population and subgroups, indicating that the serum sIL$2 \mathrm{R}$ concentration can reflect the severity of airflow limitation in AECOPD.

It has been proven that the mMRC scale is of great value in assessing the severity of dyspnoea in patients with COPD. Our data showed that the serum concentration of sIL-2R in adverse outcome of AECOPD with an mMRC score of 3 and 4 was higher than that in patients with an 
A

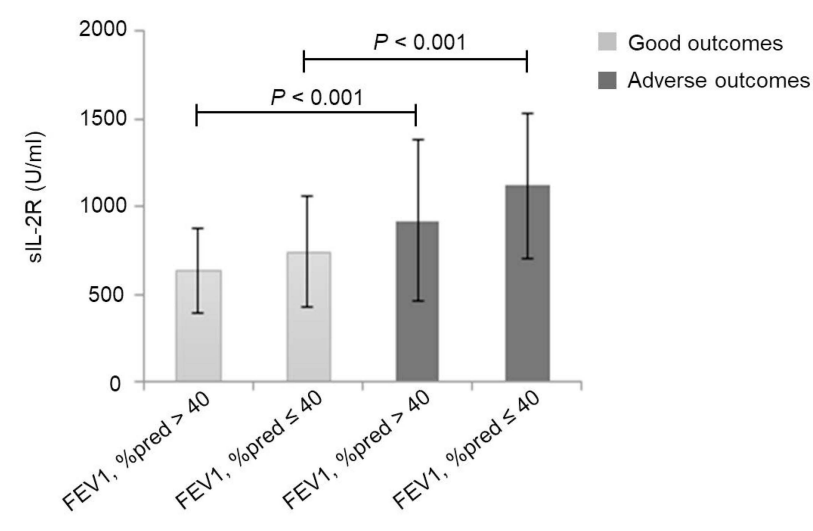

B

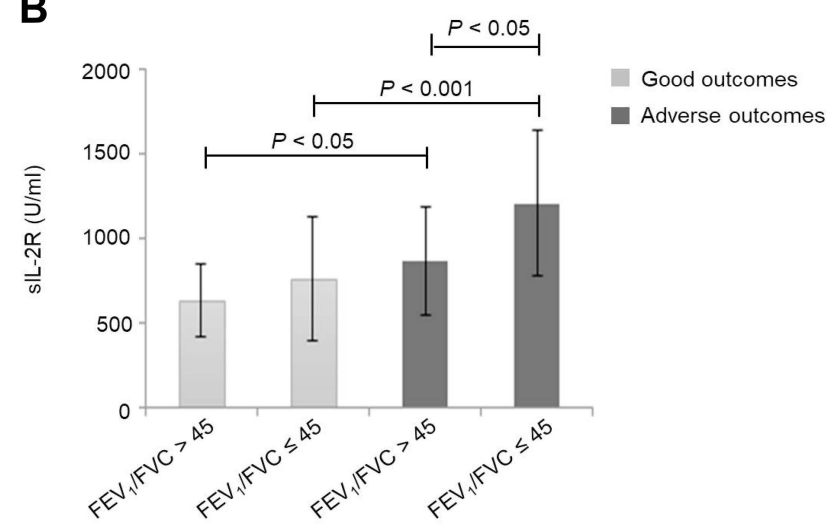

Figure 3 Relationship between $\mathrm{FEV}_{1} \%$ pred, $\mathrm{FEV}_{1} / \mathrm{FVC}$ and serum concentration of sIL-2R in good and adverse outcomes of AECOPD.

Notes: (A) In both high and low FEV $\%$ pred groups, the concentration of serum sIL-2R was higher in patients with adverse outcomes than in those with good outcomes $\left(P<0.001, P<0.001\right.$, respectively); (B) In both high and low $F E V_{1} / F V C$ groups, the concentration of serum sIL-2R was higher in patients with adverse outcomes than in those with good outcomes $(P<0.05, P<0.00$ I, respectively); Serum slL-2R concentration was higher in patients with low $\mathrm{FEV}_{\mathrm{l}} / \mathrm{FVC}$ group than in those with high $\mathrm{FEV}_{1} / \mathrm{FVC}$ group of adverse outcomes $(P<0.05)$.

Abbreviations: sIL-2R, soluble interleukin-2 receptor; $F E V_{1}$, forced expiratory volume in I second; $\mathrm{FEV}_{\mathrm{I}} / \mathrm{FVC}$, forced expiratory volume in I second/force Vital Capacity.

mMRC score of $0-1$ and 2. Frequent acute exacerbation of COPD in the preceding year is a major clinical risk factor for increased morbidity and mortality rates in the future. Our study showed that the serum concentration of sIL-2R in patients with adverse outcome of AECOPD with frequent acute exacerbations of COPD was higher than that in patients with non-frequent acute exacerbations of COPD, indicating that the serum sIL-2R concentration can be used as an indicator to predict changes in respiratory function and severity of the disease in patients with AECOPD.
Table 5 Correlation Between sIL-2R and Other Laboratory Variables in Patients with AECOPD

\begin{tabular}{|l|c|c|}
\hline Variable & Correlation Coefficient & P-value \\
\hline $\mathrm{PH}$ & -0.14774 & $\mathbf{0 . 0 0 8 6}$ \\
$\mathrm{PaCO}_{2}$ & 0.15008 & $\mathbf{0 . 0 0 7 6}$ \\
$\mathrm{PaO}_{2} / \mathrm{FiO}_{2}$ & -0.09098 & 0.1070 \\
$\mathrm{WBC}$ & 0.25015 & $<\mathbf{0 . 0 0 0 1}$ \\
$\mathrm{CRP}$ & 0.35949 & $<\mathbf{0 . 0 0 0 1}$ \\
$\mathrm{PCT}$ & 0.10383 & 0.0657 \\
$\mathrm{ESR}$ & 0.27274 & $<\mathbf{0 . 0 0 0 1}$ \\
$\mathrm{IL}-8$ & -0.01863 & 0.7419 \\
$\mathrm{IL}-6$ & 0.45888 & $<\mathbf{0 . 0 0 0 1}$ \\
$\mathrm{IL}-10$ & 0.21242 & $\mathbf{0 . 0 0 0 1}$ \\
$\mathrm{TNF}-\alpha$ & 0.14268 & $\mathbf{0 . 0 1 1 2}$ \\
\hline
\end{tabular}

Note: Bold font indicates $P<0.05$.

Abbreviations: sIL-2R, soluble interleukin-2 receptor; AECOPD, acute exacerbation of chronic obstructive pulmonary disease; WBC, white blood cells; CRP, C-reactive protein; PCT, procalcitonin; ESR, erythrocyte sedimentation rate; IL, interleukin; TNF- $\alpha$,tumor necrosis factor- $\alpha$.

In terms of inflammatory factors, our study found that sIL-2R was positively correlated with WBC, CRP, IL-6, IL-10, and TNF- $\alpha$ levels, suggesting that these inflammatory factors are associated with adverse outcomes of AECOPD, which is consistent with the results of previous studies. $^{29,30}$

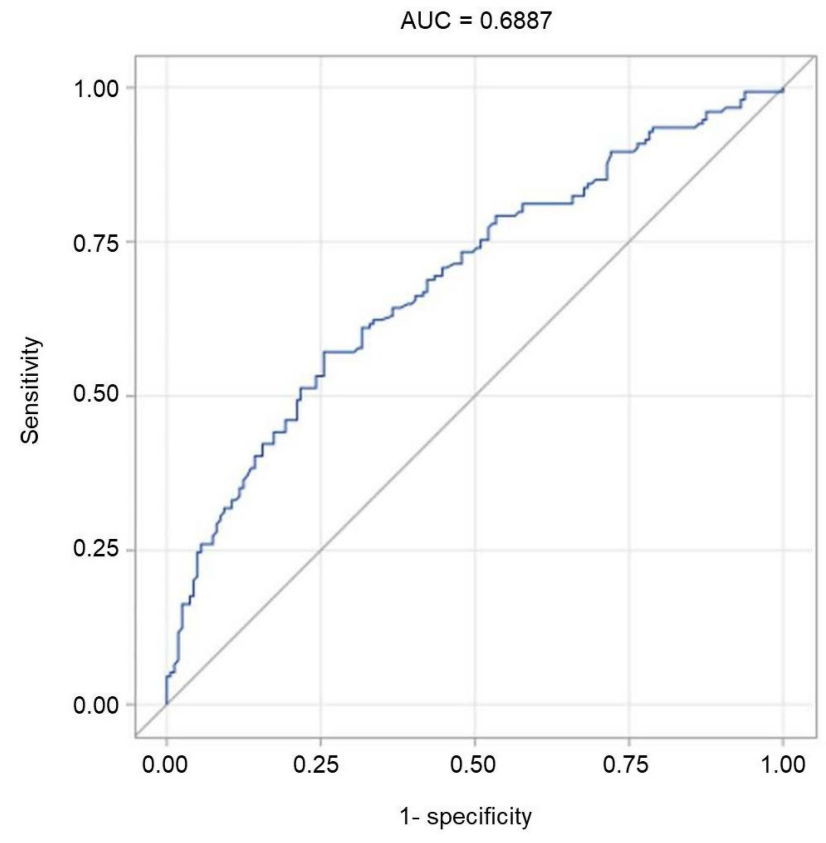

Figure 4 Diagnostic value of sIL-2R for adverse outcomes of AECOPD (AUC $=0.6887$ ). 
Immediate identification of patients with adverse outcomes of AECOPD and providing accurate treatment are extremely crucial to reduce the incidence and mortality of patients with AECOPD in the future. Our study showed that the serum concentration of sIL-2R can be used to effectively screen patients at risk for adverse outcomes of AECOPD, and the ROC curve demonstrated that the sensitivity and specificity of serum concentration of sIL-2R were $62.0 \%$ and $73.9 \%$, respectively, and the AUC reached 0.6887 .

This study had a few limitations. First, the subjects included in this study were all from a tertiary hospital, which does not reflect the general population. Second, there was a high proportion of male patients $(85.4 \%)$, which could affect the generalisability of the results. Finally, in future studies, we will need to analyse other samples that better reflect airway conditions, such as bronchoalveolar lavage fluid or sputum.

\section{Conclusion}

Our study found that the serum sIL-2R concentration was higher in patients with adverse outcomes of AECOPD than in patients with good outcomes. Increased serum sIL-2R concentration was positively associated with the GOLD grade, mMRC score, frequent exacerbation, and smoking in patients with AECOPD and negatively correlated with pulmonary function, indicating that serum sIL-2R concentration is a useful biomarker for predicting adverse outcomes in patients with AECOPD and a novel treatment target for AECOPD; thus, helping clinicians to stratify the risk of AECOPD and advancing clinical practice toward precision medicine.

\section{Abbreviations}

COPD, Chronic obstructive pulmonary disease; GOLD, Global Initiative for Chronic Obstructive Lung Disease; AECOPD, Acute exacerbation of COPD; \%pred, Percent of predicted; $\mathrm{FEV}_{1} / \mathrm{FVC}$, Forced expiratory volume/forced vital capacity; SI, Smoking index; mMRC, Modified British Medical Research Council; $\mathrm{PaCO}_{2}$, Partial arterial carbon dioxide pressure; $\mathrm{PaO}_{2} / \mathrm{FiO}_{2}$, Ratio of partial arterial oxygen pressure to the fraction of inspired oxygen; WBC, Whole blood leukocyte counts; CRP, C-reactive protein; ESR, Erythrocyte sedimentation rate; PCT, procalcitonin; IL-6, Interleukin-6; IL-8, Interleukin-8; IL-10, Interleukin-10; TNF- $\alpha$, Tumour necrosis factor- $\alpha$; sIL-2R, Soluble interleukin-2 receptor; OR, Odds ratio; CI, Confidence interval; ROC, Receiver operating characteristic; AUC, Area under the curve.

\section{Data Sharing Statement}

The datasets used and/or analysed during the current study are available from the corresponding author on reasonable request.

\section{Ethics Approval and Consent to Participate}

The study protocol was approved by the Human Research Ethics Committee of the Xinhua Hospital affiliated to Shanghai Jiaotong University Medical College (XHECC-2017-085). Written informed consent was obtained from each participant. This study was conducted in accordance with the Declaration of Helsinki.

\section{Acknowledgments}

The authors thank all miner workers who participated in this study.

\section{Author Contributions}

All authors contributed to data analysis, drafting or revising the article, gave final approval of the version to be published, agreed to the submitted journal, and agree to be accountable for all aspects of the work.

\section{Funding}

This work was supported by Hospital Foundation of Xinhua Hospital, to Yue Zhang, Shanghai Science and Technology Commission Grant of China, No:17511108502, 2017.7-2019.6.

\section{Disclosure}

The authors declare that they have no competing interests in this work.

\section{References}

1. GBD. 2017 disease and injury incidence and prevalence collaborators. Global, regional, and national incidence, prevalence, and years lived with disability for 354 diseases and injuries for 195 countries and territories, 1990-2017: a systematic analysis for the Global Burden of Disease Study 2017. Lancet. 2018;392:1789-1858.

2. Han MK, Quibrera PM, Carretta EE, et al. Frequency of exacerbations in patients with chronic obstructive pulmonary disease: an analysis of the SPIROMICS cohort. Lancet Respir Med. 2017;5(8):619-626. doi:10.1016/S2213-2600(17)30207-2

3. Hurst JR, Vestbo J, Anzueto A, et al. Susceptibility to exacerbation in chronic obstructive pulmonary disease. $N$ Engl J Med. 2010;363 (12):1128-1138. doi:10.1056/NEJMoa0909883

4. Vogelmeier CF, Criner GJ, Martinez FJ, et al. Global strategy for the diagnosis, management, and prevention of chronic obstructive lung disease 2017 report: GOLD executive summary. Am J Respir Crit Care Med. 2017;195(5):557-582. doi:10.1164/rccm.201701-0218PP 
5. Liu D, Peng SH, Zhang J, et al. Prediction of short term re-exacerbation in patients with acute exacerbation of chronic obstructive pulmonary disease. Int J Chron Obstruct Pulmon Dis. 2015;2(10):1265-1273.

6. Barnes PJ. Cellular and molecular mechanisms of chronic obstructive pulmonary disease. Clin Chest Med. 2014;35(1):71-86. doi:10.1016/ j.ccm.2013.10.004

7. Hogg JC, Chu F, Utokaparch S, et al. The nature of small-airway obstruction in chronic obstructive pulmonary disease. $N$ Engl J Med. 2004;350(26):2645-2653. doi:10.1056/NEJMoa032158

8. Charlson ME, Pompei P, Ales KL, et al. A new method of classifying prognostic comorbidity in longitudinal studies: development and validation. J Chronic Dis. 1987;40(5):373-383. doi:10.1016/00219681(87)90171-8

9. Brusasco V, Crapo R, Viegi G. Coming together: the ATS/ERS consensus on clinical pulmonary function testing. Eur Respir J. 2005;26(1):1-2. doi:10.1183/09031936.05.00034205

10. Cazzola M, Novelli G. Biomarkers in COPD. Pulm Pharmacol Ther. 2010;23(6):493-500. doi:10.1016/j.pupt.2010.05.001

11. Leeming DJ, Byrjalsen I, Sand JMB, et al. Biomarkers of collagen turnover are related to annual change in $\mathrm{FEV}_{1}$ in patients with chronic obstructive pulmonary disease within the ECLIPSE Study. BMC Pulm Med. 2017;17(1):164. doi:10.1186/s12890-017-0505-4

12. Alotaibi NM, Chen V, Hollander Z, et al. Phenotyping COPD exacerbations using imaging and blood-based biomarkers. Int $J$ Chron Obstruct Pulmon Dis. 2018;13:217-229. doi:10.2147/COPD $\mathrm{S} 152484$

13. Zheng J, Shi Y, Xiong L, et al. The expression of IL-6, TNF- $\alpha$, and MCP-1 in respiratory viral infection in acute exacerbations of chronic obstructive pulmonary disease. J Immunol Res. 2017;2017:8539294. doi:10.1155/2017/8539294

14. Sin DD, Hollander Z, DeMarco ML, et al. Biomarker development for chronic obstructive pulmonary disease. from discovery to clinical implementation. Am J Respir Crit Care Med. 2015;192 (10):1162-1170. doi:10.1164/rccm.201505-0871PP

15. Turka LA, Walsh PT. IL-2 signaling and CD4+ CD25+ Foxp3+ regulatory T cells. Front Biosci. 2008;Jan(13):1440-1446. doi: $10.2741 / 2773$

16. Malek TR, Castro I. Interleukin-2 receptor signalling: at the interface between tolerance and immunity. Immunity. 2010;33(2):153. doi:10.1016/j.immuni.2010.08.004

17. Mavropoulou E, Mechie N-C, Knoop R, et al. Association of serum interleukin-6 and soluble interleukin-2-receptor levels with disease activity status in patients with inflammatory bowel disease: a prospective observational study. PLoS One. 2020;15(5):e0233811. doi:10.1371/journal.pone. 0233811
18. Katsuya H, Shimokawa M, Ishitsuka K, et al. Prognostic index for chronic- and smoldering-type adult T-cell leukemia-lymphoma. Blood. 2017;130(1):39-47. doi:10.1182/blood-2017-01-757542

19. Bien E, Balcerska A. Serum soluble interleukin 2 receptor alpha in human cancer of adults and children: a review. Biomarkers. 2008;13 (1):1-26. doi:10.1080/13547500701674063

20. Karim AF, Eurelings LEM, Bansie RD, et al. Soluble interleukin-2 receptor: a potential marker for monitoring disease activity in IgG4-related disease. Mod Rheumatol. 2018;28(5):838-844. doi:10.1080/14397595.2017.1416739

21. van Steenbergen HW, van Nies JA, Ruyssen-Witrand A, et al. IL2RA is associated with persistence of rheumatoid arthritis. Arthritis Res Ther. 2015;17(1):244. doi:10.1186/s13075-015-0739-6

22. Shafey EM, Nagar GF, Bendary AS, et al. Serum soluble interleukin-2 receptor alpha in systemic lupus erythematosus. Iran J Kidney Dis. 2008;2:80-85.

23. Schimmelpennink MC, Quanjel M, Vorselaar AD, et al. Value of serum soluble interleukin-2 receptor as a diagnostic and predictive biomarker in sarcoidosis. Expert Rev Respir Med. 2020;14 (7):749-756. doi:10.1080/17476348.2020.1751614

24. Park CS, Lee SM, Chung SW, et al. Interleukin-2 and soluble interleukin-2 receptor in bronchoalveolar lavage fluid from patients with bronchial asthma. Chest. 1994;106(2):400-406. doi:10.1378/ chest.106.2.400

25. Peter J, Barnes FRS. Inflammatory mechanisms in patients with chronic obstructive pulmonary disease. J Allergy Clin Immunol. 2016;138(1):16-27. doi:10.1016/j.jaci.2016.05.011

26. Yang M, Kohler M, Heyder $\mathrm{T}$, et al. Long-term smoking alters abundance of over half of the proteome in bronchoalveolar lavage cell in smokers with normal spirometry, with effects on molecular pathways associated with COPD. Respir Res. 2018;19(1):40. doi:10.1186/s12931-017-0695-6

27. Xie S, Wang K, Zhang W, et al. Immunodeficiency in patients with acute exacerbation of chronic obstructive pulmonary disease. Inflammation. 2018;41(5):1582-1589. doi:10.1007/s10753-0180830-7

28. Silva BSA, Lira FS, Ramos D, et al. Severity of COPD and its relationship with IL-10. Cytokine. 2018;106:95-100. doi:10.1016/j. cyto.2017.10.018

29. Bradford E, Jacobson S, Varasteh J, et al. The value of blood cytokines and chemokines in assessing COPD. Respir Res. 2017;18 (1):180. doi:10.1186/s12931-017-0662-2

30. Fu -J-J, McDonald VM, Baines KJ, Gibson PG. Airway il-1 $\beta$ and systemic inflammation as predictors of future exacerbation risk in asthma and COPD. Chest. 2015;148(3):618-629. doi:10.1378/ chest.14-2337

\section{Publish your work in this journal}

The International Journal of COPD is an international, peer-reviewed journal of therapeutics and pharmacology focusing on concise rapid reporting of clinical studies and reviews in COPD. Special focus is given to the pathophysiological processes underlying the disease, intervention programs, patient focused education, and self management protocols. This journal is indexed on PubMed Central, MedLine and CAS. The manuscript management system is completely online and includes a very quick and fair peer-review system, which is all easy to use. Visit http://www.dovepress.com/testimonials.php to read real quotes from published authors. 